2 Taylor, R H, et al, Gut, 1977, 18, A420.

3 Ciclitira, P J, et al, Gut, 1977, 18, A419.

${ }^{4}$ Bader, J P, et al, in Proceedings of 2nd International Symposium on Histamine $\mathrm{H}_{2}$-Receptor Antagonists, ed W L Burland and M A Simkins, p 287. Amsterdam, Oxford, Excerpta Medica, 1977.

${ }^{5}$ Frost, F, et al, British Medical fournal, 1977, 2, 795.

${ }^{6}$ Englert, E, jun, et al, Gastroenterology, 1978, 74, 416.

${ }^{7}$ Dyck, W P, et al, Gastroenterology, 1978, 74, 410

${ }^{8}$ Hayes, M J, Sprackling, Margaret, and Langman, M J S, Gut, 1977, 18, 1054
${ }^{9}$ Davies, G J, Rhodes, J, and Calcraft, B J, British Medical Fournal, $1974,3,400$.

10 Hanscom, D H, and Buchman, E, Gastroenterology, 1971, 61, 585.

${ }_{11}$ Piper, D W, et al, Gut, 1978, 19, 419.

${ }^{12}$ British Medical fournal, 1977, 2, 1440.

${ }^{13}$ Freston, J W, Gastroenterology, 1978, 74, 426.

${ }^{14}$ Bodemar, G, and Walan, A, Lancet, 1978, 1, 403.

15 Machell, R J, et al, Gut, 1978, 19, A442.

\title{
Genetic basis of rheumatoid disease: HLA antigens, disease manifestations, and toxic reactions to drugs
}

\author{
G S PANAYI，P WOOLEY，J R BATCHELOR
}

British Medical fournal, 1978, 2, 1326-1328

\section{Summary and conclusions}

Ninety-five patients with rheumatoid arthritis and 200 healthy controls were examined for HLA-D-related (HLA-DR) alloantigens. HLA-DRW4 was significantly more prevalent among the patients and was particularly common in those with a family history of the disease (77\% of such patients had DRW4 compared with $34 \%$ of controls). Significantly fewer patients than controls had DRW2: patients with this antigen had rheumatoid nodules less frequently and significantly lower titres of rheumatoid factor than patients without DRW2. In contrast DRW3 was significantly more prevalent among severely affected patients with rheumatoid factor titres exceeding 1/1280 and in patients with nodules. There was a significant association between DRW2 and DRW3 and toxic reactions to sodium aurothiomalate and penicillamine.

The results suggest that the HLA-DR phenotype is associated not only with susceptibility to rheumatoid arthritis but also with severity of the disease and whether certain toxic reactions to drugs occur.

\section{Introduction}

Studies on patients with rheumatoid arthritis (RA) have shown no consistent substantial association between the disease and any HLA-A-locus or B-locus antigen $s^{1-5}$ but a highly significant association between RA and DW4. ${ }^{6}$ - Attempts to detect HLA-D-locus products serologically have led to the discovery of an allelic series of antigens that are detectable on B lymphocyres but not on most recirculating $T$ lymphocytes. These antigens correlate significantly with the HLA-D antigens and are determined either by the $\mathrm{D}$ locus or by a very closely linked locus." Owing to uncertainty whether the B-lymphocyte alloantigens are determined by the HLA-D locus itself these

Guy's Hospital Medical School, London SE1 9RT G S PANAYI, MD, MRCP, senior lecturer in rheumatology P WOOLEY, BSC, research assistant

McIndoe Research Unit, Queen Victoria Hospital, East Grinstead, Sussex RH19 3DZ

J R BATCHELOR, MD, director of research alloantigens have been provisionally designated HLA-Drelated (HLA-DR). ${ }^{9}$ One B-lymphocyte alloantigen was detected by us in $74.4^{\circ}$ ", of patients with RA but in only $27^{\circ}$ 。 of normal controls, ${ }^{10}$ and studies carried out as part of the seventh Histocompatibility Workshop and independently ${ }^{11} 1:$ have shown that the B-lymphocyte alloantigen DRW4 is significantly associated with RA.

$\mathrm{RA}$ is associated with extra-articular manifestations such as nodules, cutaneous vasculitis, peripheral neuropathy, Sjögren's syndrome, and fibrosing alveolitis. During treatment with drugs, especially gold compounds and penicillamine, toxic reactions may occur. These include rashes, proteinuria, and reduced numbers of circulating leucocytes and platelets. Some of these toxic reactions and the extra-articular manifestations may be mediated immunologically. ${ }^{13-18}$

We decided to re-examine the association between erosive $\mathrm{RA}$ and the DR antigens and investigate the possible relation between HLA antigens and extra-articular manifestations of the disease and toxic reactions to sodium aurothiomalate and penicillamine.

\section{Subjects and methods}

Ninety-five Caucasian patients with classical or definite rheumatoid arthritis according to the ARA criteria ${ }^{19}$ were studied. Except for these ethnic and clinical criteria no selection was made. The group comprised 63 women and 32 men aged 29-76 years. We looked for extraarticular manifestations both at the time of the study and retrospectively in the case notes. This disclosed 39 patients with rheumatoid nodules, five with vasculitis, nine with rheumatoid lung, and two with peripheral neuropathy. A few patients had other clinical complications, nine having Sjögren's syndrome and one Felty's syndrome.

A total of 59 patients had been given courses of either sodium aurothiomalate $(50 \mathrm{mg}$ monthly) or penicillamine (up to $1200 \mathrm{mg}$ daily) or both. Thirty had received only sodium aurothiomalate, 23 sodium aurothiomalate and penicillamine, and six only penicillamine. Toxic reactions were monitored by periodic urine analyses, blood counts, and physical examination. Since toxic reactions are particularly common during the first six months of treatment, patients had to be free of symptoms of toxicity for at least this period of treatment to be scored as drug-reaction negative.

Direct questioning was used to elicit a family history of RA and the age at onset of the disease.

\section{IMMUNOLOGICAL TESTS}

The highest recorded differential agglutination titre for rheumatoid factor as detected by the sensitised sheep red blood cell technique of Rose-Waaler was noted. This test was performed in several routine laboratories on widely separated occasions, however, so we decided to 
test for rheumatoid factor $(\mathrm{RF})$ using the latex fixation test in sera taken from the patients when they attended the survey clinic. The latex test was performed according to Singer's method ${ }^{20}$ as modified by Cats and Klein. ${ }^{21}$ All tests were carried out in our laboratory with a single batch of latex particles (Difco) and human gammaglobulin (Cohn fraction II). Tests were repeated when the results differed significantly from those of the routine laboratory; all sera were fully titred to their end-points. The results in three patients are not included here as their sera were not readily available for retesting in the confirmatory titrations.

HLA-A, B, and C antigens were identified with a conventional microcytotoxicity test in which well-validated antisera were used. Separated $\mathrm{T}$ lymphocytes were employed. For HLA-DR-antigen testing, enriched suspensions of B lymphocytes were prepared as described. ${ }^{10}$ Sera used for DR-antigen assignments were either acquired locally or gifts from numerous laboratories. All had been either directly validated in the seventh Histocompatibility Workshop or shown subsequently, in our local panel of white cell donors, to correlate with seventh workshop sera. The control panel of white cell donors consisted of 200 healthy unselected Caucasians.

\section{Results}

\section{HLA ANTIGENS AND EROSIVE ARTHRITIS}

There were no significant differences in the prevalences of HLA-A, $B$, and $C$ antigens between the patients with RA and the normal controls. Table I gives the prevalences of the HLA-DR antigens in the two groups. As observed at the seventh workshop ${ }^{11}$ and by Stastny ${ }^{12}$ a substantial and highly significant increase in DRW4 was found in the patients. A significantly lower prevalence of DRW2 was also observed.

TABLE I-Prevalences of HLA-DR antigens in 95 patients with rheumatoid arthritis and 200 normal controls

\begin{tabular}{|c|c|c|c|c|c|c|c|}
\hline \multirow{2}{*}{ Antigen } & \multicolumn{2}{|c|}{ Patients } & \multicolumn{2}{|c|}{ Controls } & \multirow{2}{*}{$\chi^{\prime \prime}$} & \multirow{2}{*}{ P } & \multirow{2}{*}{$\mathbf{P c}^{*}$} \\
\hline & No & $" 1$ & No & "." & & & \\
\hline $\begin{array}{l}\text { DRW1 } \\
\text { DRW2 } \\
\text { DRIW3 } \\
\text { DRW4 } \\
\text { DRW5 } \\
\text { DRW6 } \\
\text { DRW7 }\end{array}$ & $\begin{array}{r}10 \\
13 \\
28 \\
53 \\
6 \\
8 \\
23\end{array}$ & $\begin{array}{r}10.5 \\
13 \cdot 7 \\
29.5 \\
55.8 \\
6.3 \\
8.4 \\
24 \cdot 2\end{array}$ & $\begin{array}{l}22 \\
60 \\
54 \\
67 \\
36 \\
33 \\
59\end{array}$ & $\begin{array}{l}11 \cdot 0 \\
30 \cdot 0 \\
27 \cdot 0 \\
33 \cdot 5 \\
18 \cdot 0 \\
16 \cdot 5 \\
29 \cdot 5\end{array}$ & $\begin{array}{r}0.0 \\
8.35 \\
0.09 \\
12.35 \\
6.28 \\
2.87 \\
0.65\end{array}$ & $\begin{array}{l}\text { NS } \\
<0.0015 \\
\text { NS } \\
<0.0005 \\
<0.02 \\
\text { NS } \\
\text { NS }\end{array}$ & $\begin{array}{c}\text { NS } \\
<0.01 \\
\text { NS } \\
<0.004 \\
\text { NS } \\
\text { NS } \\
\text { NS }\end{array}$ \\
\hline
\end{tabular}

* $\mathrm{Pc}=$ Corrected $\mathrm{P}$ value (simple $\mathrm{P}$ value multiplied by 7 -that is, number of DR antigens tested)

$\mathrm{NS}=$ Not significant.

TABLE II-Prevalences of $H L A-D R$ antigens in patients with and without a family history of rheumatoid arthritis

\begin{tabular}{|c|c|c|c|c|c|c|c|}
\hline \multirow[t]{2}{*}{ Antigen } & \multicolumn{2}{|c|}{$\begin{array}{l}\text { Patients with } \\
\text { family history } \\
\qquad(\mathrm{n}==31)\end{array}$} & \multicolumn{2}{|c|}{$\begin{array}{l}\text { Patients with } \\
\text { no family history } \\
(n=62)\end{array}$} & \multirow[t]{2}{*}{$\%^{\prime \prime}$} & \multirow[t]{2}{*}{$\mathbf{P}$} & \multirow[t]{2}{*}{$\mathrm{Pc}^{*}$} \\
\hline & No & "." & No & ". & & & \\
\hline $\begin{array}{l}\text { DRW1 } \\
\text { DRW2 } \\
\text { DRW3 } \\
\text { DRW4 } \\
\text { DRW5 } \\
\text { DRW6 } \\
\text { DRW7 }\end{array}$ & $\begin{array}{r}4 \\
6 \\
3 \\
24 \\
1 \\
2 \\
5\end{array}$ & $\begin{array}{r}12 \cdot 9 \\
19 \cdot 4 \\
9 \cdot 7 \\
77 \cdot 4 \\
3 \cdot 2 \\
6 \cdot 5 \\
16 \cdot 1\end{array}$ & $\begin{array}{r}6 \\
7 \\
25 \\
27 \\
5 \\
6 \\
16\end{array}$ & $\begin{array}{r}9 \cdot 7 \\
11 \cdot 3 \\
40 \cdot 3 \\
43 \cdot 5 \\
8 \cdot 1 \\
9 \cdot 7 \\
25 \cdot 8\end{array}$ & $\begin{array}{l}7.82 \\
8.25\end{array}$ & $\begin{array}{l}\text { NS } \\
\text { NS } \\
<0.005 \\
<0.005 \\
\text { NS } \\
\text { NS } \\
\text { NS }\end{array}$ & $\begin{array}{l}\text { NS } \\
\text { NS } \\
<0.04 \\
<0.04 \\
\text { NS } \\
\text { NS } \\
\text { NS }\end{array}$ \\
\hline
\end{tabular}

$* \mathrm{Pc}=$ Corrected $\mathrm{P}$ value.

\section{FAMILY HISTORY}

Of 93 patients questioned, 31 had a family history of RA. Of these, $24\left(77^{\circ}\right)$ ) were DRW4-positive. Of the 62 patients without a family history, however, only $27\left(44^{\circ}{ }^{\circ}\right)$ had DRW4 (table II). Interestingly, DRW3 was significantly more prevalent among the patients without a family history of RA.

\section{AGE AT ONSET}

In contrast to the seventh workshop ${ }^{11}$ we did not find a significant association between early onset of the disease and the presence of
DRW4 in either sex or in all patients. Of the 85 patients on whom adequate information was available, 30 (20 women, 10 men) had their first symptoms below the age of 40 , and 55 ( 35 women, 20 men) after that age. The respective prevalences of DRW4 in these two groups were $50 \%$ and $60 \%$.

\section{RHEUMATOID FACTOR AND NODULES}

We found two significant associations between HLA antigens and RF titres. Of the 13 patients with DRW2, only three had an RF titre exceeding $1 / 80$, and the maximum observed titre of $1 / 5120$ occurred in a patient with both DRW 2 and DRW3 (table III). In contrast, out of 79 patients without DRW 2,60 had RF titres exceeding $1 / 80$. This difference was significant $\left(\gamma^{2}=12 \cdot 1 ; P<0 \cdot 001\right)$.

TABLE III-Relation between $H L A-D R$-antigen phenotypes and rheumatoid factor titre. Figures are numbers of patients.* (Numbers of patients with rheumatoid nodules given in parentheses)

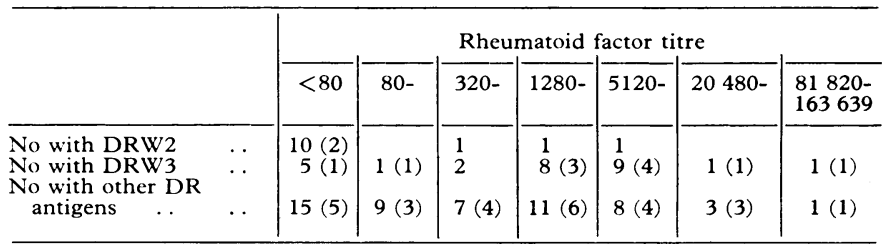

*'Two patients had both DRW2 and DRW3 (titres 1/40 and 1/5120) and are recorded twice, once in DRW2 category and once in DRW 3 category.

TABLE IV-Association between HLA-DRW2 or DRW3 or both and toxic reactions to sodium aurothiomalate and penicillamine

\begin{tabular}{|c|c|c|c|}
\hline Antigen & $\begin{array}{l}\text { Patients with toxic } \\
\text { reactions }\end{array}$ & $\begin{array}{l}\text { Patients with no } \\
\text { toxic reactions }\end{array}$ & $x^{2}$ \\
\hline $\begin{array}{l}\text { DRW2 }+ \text { DRW3 } \\
\text { Other } \ldots\end{array}$ & $\begin{array}{l}21 \\
16\end{array}$ & $\begin{array}{r}5 \\
17\end{array}$ & \} $5.17(P<0.025)$ \\
\hline
\end{tabular}

Patients with DRW3 tended to develop high RF titres, 18 out of 26 having titres of $1 / 1280$ or greater (table III). When the DRW3positive patients were compared with all the DRW3-negative patients, significantly more patients with DRW3 had RF titres of $1 / 1280$ or greater $\left(x^{2}=6 \cdot 16 ; P<0.025\right)$. Since DRW2 was associated with low RF titres, however, and most (11 of 13) of the DRW2-positive patients fell into the DRW3-negative group, the association between high RF titres and DRW3 might have been an indirect effect due to the distribution of DRW2. To determine whether DRW3 had an independent effect, all patients with DRW2 were excluded and the remainder classified as positive or negative for DRW3. Comparison between these groups showed that high RF titres $(\geqslant 1 / 1280)$ occurred significantly more often in the DRW3-positive patients $\left(\chi^{2}=3.94\right.$; $\mathrm{P}<0.05)$; thus DRW3 clearly exerted an independent effect. The association of DRW2 with low RF titres remained significant when patients with DRW3 were excluded from the analysis in a similar manner.

Rheumatoid nodules are more likely to occur in patients with high RF titres, ${ }^{22}$ and our results confirm this (table III). All our patients with RF titres exceeding $1 / 20480$ had nodules, and significantly more patients with titres of $1 / 1280$ or more had nodules than patients with lower titres $(x=4.04 ; P<0.05)$.

Interestingly, two of the 13 DRW2-positive patients but 11 of the 27 DRW3-positive patients had nodules. This difference is not in itself significant but is consistent with the significant associations of these antigens with low and high RF titres respectively.

\section{DRUG TOXICITY}

Of the 59 patients given either sodium aurothiomalate or penicillamine or both, $37(62.7 \%)$ developed toxic reactions, mostly rashes (24 patients). Ten patients developed proteinuria, often in conjunction with a rash; five developed eosinophilia, invariably with rash, and 
three developed neutropenia. Toxic symptoms were not subdivided for analysis owing to small numbers.

Patients who were positive for DRW2 or DRW3 or both appeared to have an increased risk of developing toxicity, seven out of eight patients with DRW2 and 14 out of 18 with DRW3 having reactions. Because of small numbers, patients with DRW2 or DRW3 were grouped together and compared with the remainder given gold or penicillamine (table IV). The difference between the two groups was significant $\left(\chi^{2}=5 \cdot 17 ; \mathrm{P}<0.025\right)$.

\section{Discussion}

Our results confirm the increased prevalence of a Blymphocyte alloantigen in RA, which was first reported by us ${ }^{10}$ and later identified as DRW4. ${ }^{112}$ The slight differences in prevalence between different series are not significant. We cannot, however, confirm the suggestion made at the seventh Histocompatibility Workshop that onset of RA before 40 years of age is more strongly associated with the presence of DRW4. Instead we found the greatest prevalence of DRW4 in patients with a family history of the disease $\left(77^{\circ}\right)$. DRW3 was significantly less common in patients with a family history of RA. We cannot explain this.

Fewer of the patients than of the controls had DRW2. This difference was significant even after correcting for the number of DR antigens tested (table I). One explanation is that if the prevalence of DRW4 is increased there is likely to be a corresponding decrease in the prevalence of the allelic DR antigens. We find this difficult to accept as the sole explanation, however, because, firstly, DRW2 alone among the alleles of DRW4 showed this substantial and significant deficit; and, secondly, we observed an association between the presence of low RF titres in our patients and the presence of DRW 2 .

These observations are consistent with the hypothesis that people who possess DRW2 are less likely to contract RA, and if they do are more likely to suffer a mild form with low titres of $\mathrm{RF}$ and no nodules. Interestingly, in active chronic hepatitis, patients with HLA-B7, which is in linkage disequilibrium with DRW2, are deficient in antibodies against smooth-muscle autoantigens. ${ }^{23}$

We examined possible relations between $\mathrm{RF}$ titres and the presence of particular DR antigens because of the welldocumented associations between DRW3 and a range of autoimmune diseases in which autoantibody production is thought to be pathogenic. ${ }^{811}: 4$ In addition, high titres of antibodies against smooth muscle and high titres of antinuclear factor are positively associated with DRW3 in active chronic hepatitis. ${ }^{11}$ There are also reports that in this disease the HLAB-locus antigens B8 and B12-B8 being in linkage disequilibrium with DRW3 - are associated with high titres of antibodies against rubella and measles as well as smooth muscle and nuclear antigens. ${ }^{25}$ In juvenile-onset diabetes the persistence of islet-cell antibodies occurs more often in B8-positive patients. ${ }^{26}$ The sum of this evidence suggests that possessing HLA-B8 and DRW3 influences the level of antibody titres against a variety of antigens by a mechanism as yet undefined.

In our study DRW3 was significantly associated with high titres of RF $(1 / 1280)$. This association was significant whether the group chosen for comparison was the other patients with DRW2 or those without DRW2 (the lowest titre group). Attempts were made to minimise variations in the results of testing for RF by confirming them with full titrations of all sera in a single laboratory and with use of the same reagents. We acknowledge that a single sample was tested and that any variations in titre with time were not taken into account.

Our results, and those of others cited, suggest that DRW2 and DRW 3 are genetic markers for contrasting types of immune responsiveness. But although contrasting tendencies to form $\mathrm{RF}$ were observed, no measurements of cellular immunity were made; and it cannot be assumed that cellular immune responsiveness will necessarily be similar to antibody responsiveness.
The possession of HLA-B27 is positively associated with an increased risk of adverse reactions to levamisole in patients with RA. ${ }^{27}$ As many of the toxic complications of sodium aurothiomalate and penicillamine are thought to have an immunological basis,,$^{13}{ }^{18}$ it seems plausible to expect an association of such complications with products of genetic loci that are either themselves concerned in or closely linked to other controlling immune responsiveness. In our series a significant excess of treated patients developing toxic complications had DRW 2 or DRW3. Clearly this finding must be interpreted cautiously and needs to be confirmed. Nevertheless, it does point to the possible importance of immunogenetic factors in toxic complications of drug treatment in other diseases.

We express our sincere thanks to Dr R Grahame and Dr T Gibson for allowing us to study some of their patients. The work was financed by grants from the Arthritis and Rheumatism Council and the Medical Research Council. We thank Mrs L Simmons, Mrs C Seymour, and Mrs G Clare for expert technical help.

\section{References}

Lies, R B, Messner, R P, and Troup, G M, Arthritis and Rheumatism, $1972,15,524$.

- Seignalet, J, et al, Vox Sanguinis, 1972, 23, 468

Kueppers, F, Brackertz, D, and Mueller-Eckhardt, (C, Lancet, 1972, 2,1425 .

Schlosstein, L, et al, New England fournal of Medicine, 1973, 288, 704.

Nyulassy, R, et al, Lancet, 1974, 1, 450.

'Stastny, P. Transplantation Prociedings, 1975, 7, 57.

Stastny, P, fournal of Clinical Investigation, 1976, 57, 1148

Bodmer, W F, in Histocompatibility Testing 1977, ed W F Bodmer, et al. Copenhagen, Munksgaard. In press.

9 WHO-IUIS Terminology Committec, in Histocompatibility Testing 1977, ed W F Bodmer et al. Copenhagen, Munksgaard. In press.

1" Panayi, G S, and Wolley, P H, Annals of the Rheumatic Diseases, 1977, 36, 365 .

"Batchelor, J R, and Morris, P J, in Histocompatibility Testing 1977, ed W F Bodmer, et al. Copenhagen, Munksgaard. In press.

1.2 Stastny, P, Nez" England fournal of Medicine, 1978, 298, 869.

${ }^{13}$ De Horatius, R J, Abruzzo, J L, and Williams, R C, Archives of Internal Medicine, 1972, 129, 441

11 Zvaifler, $\mathrm{N}$ J, in Advances in Immunology, ed E J Dixon and H G Kunkel, vol 16. London, Academic Press, 1973.

${ }_{15}$ Davies, P, et al, British Medical fournal, 1973, 3, 676.

${ }_{16}$ Denman, E J, and Denman, A M, Annals of the Rheumatic Diseases, 1968, 27, 582 .

1: Bacon, P A, et al, Quarterly Fournal of Medicine, 1976, 45, 661.

1* Weitzman, S A, Stossel, T P, and Desmond, Mary, Lancet, 1978, 1, 1068.

${ }^{19}$ Ropes, M W, et al, Annats of the Rheumatic Diseases, 1959, 18, 49.

2 "Singer, J M, Bulletin on Rheumatic Diseases, 1974, 24, 762.

${ }^{21}$ Cats, A, and Klein, F, Annals of the Rheumatic Diseases, 1970, 29, 663

22. Kellgren, J H, and Ball, J, British Medical fournal, 1959, 1, 523.

${ }^{23}$ Eddleston, A L W F, and Williams, R, British Medical Bulletin, 1978, 34, 295.

24 British Medical Bulletin, 1978, 34, No 3

25 Galbraith, R M, et al, Lancet, 1976, 1, 930

26 Morris, P J, et al, Lancet, 1976, 2, 652.

27 Vevs, E M, Mielants, H, and Verbruggen, G, Lancet, 1978, 1, 148.

(Accipted 20 Siptember 1978)

ONE HUNDRED YEARS AGO SIR,-Will you allow me to ask the attention of your readers to a suggestion, which has, I think, some practical bearing on the prevention of hydrophobia ? Would it not be well, in crowded communities like ours, where dogs are but little needed for the chase, to compel, by law, the removal of the canine teeth? The small number of dogs in which these teeth are required for special purposes might be exempted. It is the formidable canine tooth which, in nine bites out of ten, does the damage; without it, few dogs would be able to bite through clothing, for instance, and, in their attacks on each other, they would probably usually fail to break the skin. There would be but little suffering involved in the extraction, and the dogs themselves would be great gainers, not only in the diminished risk of rabies, but also in that they would not inflict on each other nearly so much pain in their ordinary quarrels.-I am, sir, yours, etc, JoNATHAN Hutchinson. (British Medical fournal, 1878.) 